\title{
Students' Computer Skills and Advertising Course Performance
}

\author{
LOUISA HA, FRED BEARD AND ROY KELSEY
}

General computer knowledge and literacy are essential in the education of today's advertising practitioner. While research suggests the availability and use of computers has become widespread in advertising education (Kendrick, 1995), there is little research to confirm that students are acquiring the computer literacy and general knowledge they need to successfully make the transition from campus to workplace. Furthermore, despite the fact that use of computers in higher education appears to have reached a "critical mass" (DeLoughry, 1996), there is little evidence regarding the extent to which general computer knowledge contributes to education outcomes, such as improved course performance.

This article examines the role computer knowledge may play in the accomplishment of short-term advertising course educational outcomes, as well as the longterm goal of improving advertising education.

\section{Background}

Computer technology has been investigated extensively as an instructional technology. Less frequently examined, however, is the issue of basic computer knowledge and literacy and its relationship with academic performance. Increasing exposure for students to computers in higher education (Arant 1996; DeLoughry, 1996; Kendrick, 1995), elementary/secondary schools, as well as the potential for an emerging gap between technological "haves" and "have-nots," clearly suggests the importance of examining the issue of prior computer knowledge and its relationship with advertising course performance.

Yet, despite the rather intuitive assumption that student computer knowledge should be associated with higher levels of performance in college courses, few studies have attempted empirically to examine this issue. For instance, Reed (1990) found that students, who were instructed to use computers during a semester-long English course, soon began to develop more effective ways to accomplish their courserelated work with the computer. Unfortunately, he did not address the possibility that prior general computer knowledge might have affected the students' performance in the course. Novitzki (1991), in his study of business administration pro-

Ha (LOUISA_HA@GALLUP.COM) is research director at The Gallup Organization; Beard is assistant professor, and Kelsey is associate professor of journalism and mass communication at the University of Oklahoma, Norman. 
grams, found that when the emphasis on computer instruction in a course is focused on applications needed for students to understand course content, the students' performance in the course is likely to increase with their computer knowledge.

Advertising faculty generally have been positive toward the use of computer technology. For example, Kimbrough (1992) sees the computer as a powerful stimulus for creativity. Alvey (1992) contends that computer technology can improve students' work in advanced level courses. Barnes (1996) reports that over one-third of her students visited Web sites on their own after her demonstration in the class. In their examination of the Internet as a teaching tool, Farnall and Geske (1996) developed a Web site and used it, and other resources on the Web, as an instructional strategy in two sections of an advertising creative strategy course. Their results indicate that students in the two Internet sections performed better in the course, based on midterm exam scores and individual student projects. Thus, their study suggests that computer knowledge, at least in the form of Internet knowledge, may be associated with improved course performance. However, the study did not differentiate between types of performance assessments, e.g., exams vs. computer-based assignments.

In contrast to the faith in the potential of using computer to enhance learning shown by the advertising faculty discussed above, Smith's (1994) experiment of using computer-mediated communication in his three media law classes shows noimprovement in students' course performance and, further, that it can arouse objections from the students.

One of the most extensive studies of student general computer knowledge is Geissler and Horridge's (1993) survey of 790 students enrolled at a large university in the southwest. One of the goals of this study was to predict computer knowledge levels of students. Their study found that students who own computers rated themselves significantly higher in all areas of computer competence than those who did not own a computer. Notably, those who claim to have higher computer knowledge in five of the six computer competence areas have lower G.P.A.s. They also found that students in business administration said they had significantly higher levels of computer knowledge than other majors in four of the six competency areas. Males reported significantly higher levels of computer knowledge, compared to females, in three of the competency areas.

In a scathing criticism of the value of computers in higher education, Shields (1996) argues that, "There's little basis for believing that computers have helped to alter, let alone transform, the cognitiveintellectual capabilities students need to develop in college ... "(p. 43). Thus, it seems imperative to examine in what specific ways general computer knowledge may be associated with better performance in advertising courses.

\section{Questions and hypotheses}

The primary purpose of this study is to identify the computer knowledge levels of college students enrolled in advertising courses and, further, to examine the relationships between this knowledge and performance in the courses. This was accomplished by identifying students' present levels of general computer knowledge and literacy in several usage areas, and students' performance in advertising courses in three performance areas. The following questions were addressed in this study:

1. What is the general computer knowledge level of students enrolling in advertising courses? How great are the differences in computer knowledge levels between advertising majors, marketing majors and other majors?

2. Does prior computer knowledge provide a competitive edge to students in their advertising course performance? 
3. In what areas does computer knowledge enhance course performance?

In addition, the discussion presented earlier in this article leads to the following hypotheses:

H1. General computer knowledge correlates positively with course performance assessments that highly involve computer skills;

$\mathrm{H} 2$. Internet knowledge correlates positively with course performance assessments that involve some or high computer skills; and

H3. General computer knowledge does not enhance students' performance in assessments that involve no computer skills (e.g., exams).

\section{Method}

Data-gathering for this study involved the tracking of scores and prior computer knowledge levels; thus, it was not feasible to conduct a random sample of schools. Controlling computer knowledge levels of students through assignment of groups in different classes using experimental designs was also out of consideration because no school can assign students into different advertising classes based on their computer knowledge levels. The survey method was deemed the most appropriate way to conduct the study.

To collect information on student computer knowledge levels, a self-administered survey questionnaire was distributed to all students enrolled in the advertising classes that the authors taught between August 1995 and December 1996 (summer courses excluded). These classes were offered in the marketing department and the journalism department respectively in two public universities in the United States with comparable student populations. One university is located in the Midwest and the other is located in the Southwest. The advertising classes ranged from Introduction to Advertising to the capstone course of Advertising Campaigns in the journalism program (Table 1 is a list of the

\section{TABLE 1 \\ List of Courses Under Study}

Percent of Student Cases

Introduction to Marketing Communication $\quad 44.6$

Advertising Management

12.6

Advertising Research

10.9

Advertising Media

5.8

Introduction to Advertising

10.2

Advertising Campaigns

2.0

Copy and Layout

Contemporary Problems in Advertising $(n=294)$

Note: The first four courses were taught by the same instructor, the other four courses were taught by two other instructors who taught two courses each.

courses used in this study). A total of eight courses and 12 classes were covered in this study, which represented all the core courses in the advertising sequence or advertising option in each of the universities under study.

At the beginning of the courses, the students filled out the questionnaire as student information sheets for the faculty members. To facilitate students providing candid assessments of their computer knowledge levels, the students were assured that their questionnaire responses would not affect their grades in the courses. The questions on knowledge about specific computer software was open-ended so that students could freely write the name of any software packages they knew. To aid them in matching software programs with types of applications, three to four examples were given in each application category. Computer knowledge was divided into four application types in this study:

1. Word processing or desktop publishing software such as Microsoft Word, WordPerfect, and PageMaker;

2. Internet communication tools such as e-mail, the World Wide Web, gopher, and file transfer protocol (ftp);

3. Statistics and spreadsheet software 
such as Lotus 123, Microsoft Excel, and SPSS-PC.; and

4. Graphics and presentation software such as Aldus Freehand and Harvard Graphics.

The knowledge score for each student was computed by summing the number of tools or software programs that the student reported knowing in each application type. Although this only indicated the breadth of the computer software knowledge of students, it would have been difficult to measure actual knowledge more rigorously without having students take an aptitude test on each program they reported knowing. However, it is reasonable to assume that the more software programs they know about in a certain application area, the more they know about how to use a computer in that area.

This study is a preliminary research on the relationship between prior computer knowledge levels and advertising course performance. Its goal is to cover the whole core advertising curriculum in both marketing schools and journalism schools so that the findings can be applicable to different advertising programs in other colleges. The authors were only interested in the extent computer programs were involved in course performance assessments, not specific assignments in each course. Therefore, course performance of the students was measured by the type of scores they attained in each course at the end of the semester.

The scores for each course were categorized into three types: (a) non-computer related assessment scores such as exams and term papers; (b) partial computer-related assessment scores such as group projects which students may use, at their discretion, Internet research skills, graphics and word processing skills; and (c) computer-based scores that require students to use a certain computer program to accomplish an assignment, such as an advertisement created with PageMaker in the Copy and Layout class. To facilitate com- parison across courses, all the scores were standardized into percentages. The total score was used as a reference to compute the overall performance of the student in that course. In this study, any course with multiple sections was taught by the same instructor; thus, the confounding effect of different instructors is eliminated. The scores can reflect a consistent grading scheme of the same instructor for each course.

The unit of analysis of this study was a student case in each course. If a student enrolled in two courses under this study, he or she would become two cases in the statistical analysis. The only exception was in the analysis of the general computer knowledge levels of students in which the individual student was the unit of analysis to avoid bias caused by counting some students twice. This study did not exclude students enrolling in more than one course in the analysis of course performance for two reasons. First, students can perform well in one course and perform poorly in another course. By including students enrolled in more than one course, we could attribute the results to the course rather than individual differences among students. Second, we have no justification to exclude students enrolling in more than one course because they were allowed to enroll in several courses at the same time and they would take progressive courses in different semesters. We would not be using a probability sample if we excluded them from the study. Furthermore, additional bias would be caused by excluding them. Using individual cases in each course increased the reliability of the results of this study across courses. The results due to chance would be minimized.

\section{Statistical analysis}

We do not presume that computer knowledge level is the only factor that determines a student's performance in a course. Many reasons can contribute to a student's performance such as the student's interest 
in and prior knowledge about the course content. Nevertheless, computer knowledge may positively contribute to learning outcomes in certain portions of a course. Therefore, significance tests and correlation statistics were used to analyze the relationship between computer knowledge levels and course performance. T-tests or chi-square tests of significance were used in the study depending on the number of groups. T-tests were used in two group situations such as comparing the mean difference in computer knowledge between gender and the two universities. Chi-square tests were used in three group situations such as comparing the difference in computer knowledge among the three different majors. Because majors were measured on a nominal scale while the dependent variable, computer knowledge level, was measured on an interval scale, we used the Eta statistic to indicate the strength of the association between these two variables (Norusis, 1988). Finally, Person's Correlation Coefficients were computed to indicate the strength of the association between prior computer knowledge and course performance.

\section{Results}

The student sample. A total of 244 individual students (294 student cases) were analyzed in the study. Sixty-three percent of the respondents took the advertising courses offered by the marketing department of the Midwestern university, and 37 percent enrolled in the advertising courses offered by the advertising sequence in the school of journalism at the Southwestern university. The gender distribution of respondents was equal between males and females. All the students were either juniors or seniors in class standing.

Most of the advertising courses in this study were open to all majors. As a result, the respondents of this study were comprised of 42 percent business majors, 37 percent advertising or communicationrelated majors, and 21 percent other majors such as fashion merchandising, sports management, and visual communication technology.

Similar to the faculty estimates in the national study by Kendrick (1995), about 44 percent of the respondents owned a computer at home. Macintosh computers, as students' home computers, were less popular than IBM compatibles. Among those that owned computers at home, 63 percent owned an IBM or compatible.

General computer knowledge level. One should bear in mind that most college students learn computer software on their own without taking classes. The few courses mandating the use of a desktop publishing programs such as PageMaker in the copy and layout class are the major sources of formal training they have on a software package.

Table 2 shows that among the four computer applications investigated in this study, word processing was the most widely used. On average, students knew two word processing programs and 1.6 Internet communication tools, but had very little or no knowledge about statistics or spreadsheet applications (mean $=0.8$ ), and graphics applications (mean $=0.7$ ).

Consistent with Geissler and Horridge's (1993) results, students who owned a computer at home tended to report higher knowledge levels on some of the computer applications than those who did not own a computer at home $(r=.21, p$ $=0.001$ ). The strongest advantage for those who owned a computer at home was knowledge of Internet communication tools ( $r=$ $.25, p<0.0001$ ). Owning a computer at home was also associated with reporting higher knowledge levels of graphics and presentation programs $(r=.17, p=0.01)$. Nevertheless, there were no significant relationships between owning a computer at home and knowledge of word processing applications ( $r=0.08$, n.s.) or statistical applications ( $r=0.02$, n.s.).

Word processing. Microsoft Word $(84 \%)$ and Word Perfect $(65 \%)$ were the two word processing software programs 


\section{TABle 2 \\ Types of Computer Application Software KNOWn by Respondents *}

\author{
Word Processing/Desktop Publishing \\ Microsoft Word \\ $83.9 \%$ \\ Word Perfect \\ $65.3 \%$ \\ PageMaker \\ Other (e.g., Write now) \\ $28.2 \%$ \\ $21 \%$
}

Internet Communication Tools

The World Wide Web

$56.9 \%$

E-mail

$55.3 \%$

Gopher

$32.7 \%$

FTP

$10.1 \%$

Spreadsheet and Statistics

Microsoft Excel

$34.3 \%$

Lotus 123

$28.6 \%$

Cricketgraph

$3.6 \%$

SPSS-PC

$2.4 \%$

Other (e.g., Quattro Pro)

Graphics

MacPaint

$21.8 \%$

Other (e.g., Photoshop)

$18.1 \%$

Freehand

$10.1 \%$

PowerPoint

$9.3 \%$

Harvard Graphics

$8.1 \%$

$n=244$

"Multiple-response items

used most by students. Less than one-third of the respondents knew any desktop publishing programs such as PageMaker.

Internet communication tools. Although the Internet is a rather new technology on most college campuses, it has been experimented with by quite a large proportion of students. Fifty-seven percent of the respondents knew how to use a browser to access the World Wide Web; and 55 percent knew how to use e- mail. The student with the most experience in using e-mail had only 3.5 years of experience. The average e-mail usage experience was only 4.4 months. More than half of those who used e-mail checked it every day or several

times a week. Frequency in using e-mail is positively correlated with the length of time respondents have been using e-mail. The longer the time they have used e-mail, the more often they check their mail ( $r=$ .53, $p<0.001$ ). Almost one-third of the respondents reported knowing how to use Gopher, the Internet navigation tool. The least known Internet communication application was file transfer protocol (ftp), which enables one to upload or download files from the Internet. Only 10 percent of the respondents knew how to use it.

Spreadsheets and statistics. Students' knowledge about spreadsheets and statistics (computation) applications was generally low. Among those who knew this application, Microsoft's Excel (34\%) and Lotus $123(29 \%)$ were the two most frequently used. Cricketgraph (a Macintoshbased program used to create graphs and charts) and SPSS-PC (a PC-based statistical software program), were much less popular with only 4 percent and 2 percent of students respectively knowing how to use them. Other spreadsheet software programs with which students were acquainted include Quattro Pro and Paradox.

Graphics and presentations. Graphics and presentation software programs were the least known computer applications among the respondents. MacPaint was a graphic program that slightly more than one-fifth of the respondents $(21.8 \%)$ mentioned using. Only 10 percent of the respondents knew Aldus Freehand. Power Point and Harvard Graphics, which are commonly used presentation programs in the business world, were known by less than 10 percent of the respondents. Some students indicated that they knew quite a few other graphic software packages such as Adobe Photoshop and CorelDraw.

Difference between majors. Comparisons were made between business majors, advertising/communication majors, and other majors on their computer knowledge levels as shown in Tables 3 and 4. Interest- 
ingly, out of the four applications, only two applications show significant differences among majors. There were no significant differences in Internet communication tool knowledge $\left(\chi^{2}=10.52, d f=8, p=.23\right)$, and graphics and presentation knowledge $\left(\chi^{2}=\right.$ $12,71, d f=8, p=.12$ ). Yet communication majors and business majors differed significantly in spreadsheet knowledge and word processing/desktop publishing knowledge. Namely, business majors had much higher knowledge levels about statistics and spreadsheet programs than advertising/communication majors and other majors $\left(\chi^{2}=40.4, d f=6, p<0.0001\right.$, Eta $=$ .38), while advertising/communication majors had much higher knowledge levels in word processing and desktop publishing programs than other majors $\left(\chi^{2}=22.7\right.$, $d f=6, p<0.0001$, Eta $=.25$ ).

University and gender differences.

The two universities under study offer comparable levels of computer facilities. Both offer free e-mail services to students and have public computer labs housed in the same main building as the department. It should be noted that the computer platforms that each department under study uses for teaching were different, but representative of many universities. The computer platform of the marketing department is the IBM PC while its journalism counterpart is Macintosh. It is possible that such differences might have affected the computer knowledge levels of students. The knowledge of each computer application of the students in each school was compared to ensure that the results were not confounded by the schools or programs that were chosen.

When a comparison of the mean knowledge score of each application between the two universities was conducted using t-tests, no significant differences in most of the computer applications were found, with one exception. Students in the university where advertising was taught in the journalism department had a slightly higher mean score in word processing/

\section{TABLe 3}

Word Processing/Desktop Publishing Software Applichtion Knowledge by Majors

Number of

$$
\begin{aligned}
& \text { Business Advertising/ Other Majors } \\
& \text { ( } n=101) \text { Communication ( } n=52) \\
& (n=88)
\end{aligned}
$$

software

None

1

5

2.2

26.7

17

2

51.4

35.2

53.7

$\begin{array}{llll}3 \text { or more } & 16.9 & 45.4 & 19.2\end{array}$

$\begin{array}{llll}\text { Total } & 100 & 100 & 100\end{array}$

Note: All figures are in percent

$\chi^{2}=22.7, d f=8, p<0.0001$

$\mathrm{Eta}=.25$

\section{TABLE 4}

SpreadsheEts and Statistical

\begin{tabular}{|c|c|c|c|}
\hline \multirow[b]{2}{*}{$\begin{array}{l}\text { Number of } \\
\text { software }\end{array}$} & \multirow[t]{2}{*}{$\begin{array}{c}\text { Business } \\
(n=101)\end{array}$} & \multirow[t]{2}{*}{$\begin{array}{c}\text { Advertising/ } \\
\text { Communication } \\
(n=88)\end{array}$} & \multirow[t]{2}{*}{$\begin{array}{l}\text { Other Majors } \\
\quad(n=52)\end{array}$} \\
\hline & & & \\
\hline None & 21.8 & 48.9 & 71.2 \\
\hline 1 & 47.5 & 34.1 & 25 \\
\hline 2 & 25.7 & 15.9 & 1.9 \\
\hline 3 or more & 5 & 1.1 & 1.9 \\
\hline Total & 100 & 100 & 100 \\
\hline $\begin{array}{l}\text { Note: } \text { All fig } \\
\chi^{2}=40.4, \mathrm{~d} \\
\mathrm{Eta}=.38\end{array}$ & $\begin{array}{l}\text { res are in } \\
6, p<0 .\end{array}$ & $\begin{array}{l}\text { percent. } \\
0001\end{array}$ & \\
\hline
\end{tabular}
SofTWARE APPLiCation KNOWLEDGE BY MAJORS

desktop publishing skills than students in the university where advertising was taught in the marketing department $(t=-2.1, p=$ $0.037)$. This might be explained by the fact that PageMaker, a desktop publishing program, was taught in the copy and layout class in the journalism department, but not in any course in the marketing department of the other university.

Many computer usage studies have found that males are more likely to use computer technology, especially the Internet, than females (e.g., GVU's World Wide 
Web User Survey, 1996). To examine if this holds the same for the college students in this study, the gender of the respondents and their mean score in each computer application was compared by one-tailed ttests because males were presumed to have higher scores than women. The notion that males have more computer knowledge was partially supported in this study. In terms of overall general computer knowledge, males scored slightly higher than women ( $t$ $=1.72, d f=242, p<0.05$ ). Males were indeed particularly strong on the Internet communication tools ( $t=2.71, d f=242, p$ $<0.05)$ and to a lesser extent, graphics and presentation programs $(t=2.35, d f=242, p$ $<0.05$ ). Nevertheless, there were no significant differences between males and females in statistical applications $(t=0.2$, $d f=242$, n.s.) and word processing skills ( $t$ $=-1.5, d f=242$, n.s.)

Prior computer knowledge and course performance. In contrast to the findings of previous studies by Reed (1990), Novitzki (1991), and Farnall and Geske (1996), which suggest computer knowledge could enhance course performance, this study found no relationship between prior computer knowledge and overall performance in an advertising course ( $\mathrm{r}=$ $0.023, \mathrm{n} . \mathrm{s}$.). In other words, prior computer knowledge does not appear to give students a competitive edge in their performance in a course. To further explore if the knowledge of a particular computer application facilitates performance, each com- puter application area was correlated with the overall course performance score. None of the applications have any significant relationship with overall course performance (Internet, $r=-0.085$, n.s.; Word Processing, $r=0.06$, n.s.; Graphics Presentation, $r=-0.052$, n.s.; Statistics, $r=0.057$, n.s.). Even after controlling for gender, university, and major with partial correlations, the correlation coefficients were still insignificant, indicating the lack of a statistically significant relationship between prior computer knowledge level and overall course performance.

Where computer knowledge helps. To investigate whether certain computer application knowledge might enhance student performance in a particular aspect of a course, each computer application knowledge level was correlated with each type of assessment: computer-based, partial computer-related, non-computer-based, and total score. The distribution of the course performance scores is shown in Table 5 .

Hypothesis 1 proposes that general computer knowledge correlates positively with course performance assessment on computer-based assignments. The results of this study did not support this hypothesis because there was no significant correlation between general computer knowledge score and the computer-based assessment scores ( $r=-.08$, n.s.).

Hypothesis 2 proposes that prior knowledge of Internet communication tools facilitates students' performance in partial

\section{Table 5 \\ Distribution of Course Performance Scores USED IN THE STUDY}

$\begin{array}{lrrrr} & n^{*} & \text { Range } & \text { Mean } & S D \\ \text { Computer-based score } & 59 & 57-76 & 80 & 9.4 \\ \text { Partial computer involved score } & 225 & 45-100 & 88 & 8.2 \\ \text { Non-computer related score } & 294 & 30-98 & 80 & 8.5 \\ \text { Total score } & 294 & 48-100 & 85 & 7.6\end{array}$

* The $n$ represents all the cases that contain that measure of performance in the eight courses.

Note: All figures are in percent 
computer involved or computer-based assignments. Examples of partial computer involved assignments are the use of the Internet to do research or the use of combinations of graphics and word processing or even statistics software such as course projects and presentations. An example of a computer-based assignment is a secondary research report using the World Wide Web. This hypothesis was also rejected because there were no significant correlations between the Internet knowledge score and performance in either partial computer involved assignments $(r=.07, \mathrm{n} . \mathrm{s}$. $)$ and computer-based assignments $(r=-.08$, n.s.). Such non-significant relationships still hold true even if the application was specific to the assignment, such as knowledge of the World Wide Web and an assignment of conducting research on the World Wide Web, or the knowledge of PageMaker in a Copy and Layout assignment.

Hypothesis 3 indicates the limitation of computer knowledge level in enhancing course performance. It does not appear to aid a student at all if the course assessment, such as an exam, does not involve any computer skills. This hypothesis was supported as there was no significant relationship between computer knowledge level and non-computer involved assessment scores ( $r=0.007$, n.s.).

\section{Discussion and conclusion}

Many administrators and educators in higher education have put high hopes on computer technology to improve student learning, while critics have worried about its effectiveness and the widening knowledge gap among students in computer technology. The results of this study suggest both good and bad news. The good news is that prior computer knowledge does not give a student any competitive advantage in any kind of course performance measure across the eight advertising courses under study, at least for the students in the present sample. It seems the "haves" may not pose a significant threat to the "have-nots" in a course. Therefore, even if students have no knowledge of a computer application, as long as they are willing to learn in a course, they are not at a disadvantage compared to those who have prior knowledge using certain computer applications. As educators, we do not need to worry so much about the students' prior computer knowledge as this study has shown that students with different knowledge levels competed on an equal plane even if the course required the use of specific computer programs. Students can learn new computer applications with equal aplomb.

The finding that there is no relationship between prior computer knowledge level and course performance, even in computer-based assessments, has two implications for advertising education. First, many students are not yet computer literate. Students who claimed to know a variety of computer programs did not necessarily know how to use them to improve the substance of their work. For example, while they may have been capable of using the Internet to conduct secondary research or statistics software to perform more sophisticated analyses of data, the findings reported here indicate that they did not necessarily do so. Another implication is that instructors, when grading assignments, look not only at the appearance of the work (in which using a computer can help), but also at the substance or content of the student's work. This dispels many students' belief that the more time they spend on "packaging" an assignment, the better the score they will get from instructors. Educators not only need to educate students on the importance of substance in any assignments, but also have to show their students how appropriate use of different computer applications can improve the substance of the work.

The bad news is that, especially to technology advocates, the findings of this study may seem to be a blow to the optimism regarding the contributions computer 
technology may bring to advertising education. Universities continue to divert many of their precious resources to investing in computer technology. Unfortunately, the returns from this investment may not be as high as the expectations for them. At least
Computer skills may be important for college students to get entry-level jobs. Yet, industry professionals indicate that such skills are only a preferred, but not expected, qualification (Rappoport, 1996). They place more importance on other aspects of the candidate such as personality and problem-solving ability (Wagner, 1992). Keeping this in mind, educators must not let the high-technology trend in advertising education overshadow the fundamentals of a college advertising education (the cultivation of intellectual ability, the mastery of the subject matter, and the development

we have found that prior computer knowledge makes little contribution to a student's performance in any advertising course.

The current knowledge level of students in computer applications shown in this study indicates a weakness students may experience in competing for jobs in the business world, especially advertising or communication-related majors. Many of them did not know any presentation programs or statistical packages, both of which are commonly used in the business world. In competing for jobs that require formal presentations, the students would be at a disadvantage. More importantly. presentations or statistical applications are often not required in classes. They are usually optional and may be used in a group setting in which only one member does all the design or statistical work. Many students might not be able to see the need to learn such applications. Faculty members might want to emphasize the importance of knowing such applications. One way to do so is by giving individual assignments that require the use of some of the commonly used presentation or statistical software applications. Certainly, such strategies should be contingent upon the availability and accessibility of computer facilities at the university. of critical thinking skills).

\section{Limitations and suggestions}

Nevertheless, this study is limited in two respects. It did not examine the use of computer technology as a teaching tool, which means the employment of a customdesigned computer application as an instructional strategy. The present study only examined students' prior and current knowledge of commercial computer software programs as a predictor of course performance. Second, not all of the eight courses under study required the use of computer applications. Only three courses had totally computer-based assignments: Copy and Layout, Advertising Research. and Advertising Media. In other classes. the use of computer applications was largely dependent on the individual student's choice. Nonetheless. such presence of computer-based, partial computer involved and non-computer related assignments reflects the reality of an advertising curriculum. Many advertising programs still use a combination of courses of which some use computers heavily. some use computers at the discretion of students, and some do not use any computers in their course assignments.

Finally, this study's measures of com- 
puter knowledge are far from perfect. The diverse sample of classes and universities that we used forbade us conducting a detailed test of computer knowledge. Simply measuring an individual's knowledge of one computer program is already a very complex task that deserves a specialized study. More sophisticated measures of students' computer knowledge can be developed in future research to further understand their ability to apply different functions of a computer program that is related to a course. We can identify key areas that we would like students to know in a program and ask the students to perform tasks of those areas as a verification of their knowledge or competency in those areas.

Alvey, P. A. (1992). Teaching advertising courses using computers: Lessons from a leading edge. In L. N. Reid (Eds.), Proceedings of the 1992 Conference of the American Academy of Advertising (pp. 13-14).

Arant, M. D., Jr. (1996, August). The use of online resources in teaching journalism and mass communication. Paper presented at the meeting of the Association for Education in Journalism and Mass Communication.

Barnes, B. E. (1996). "Introducing introductory advertising students to the world wide web." Journal of Advertising Education, 1(1), 5-12.

DeLoughry, T. J. (1996). "Reaching a ëcritical mass." The Chronicle of Higher Education, 42(20), A17-A18.

Farnall, O., \& Geske, J. (1996, August). The Internet as a teaching tool in advertising education.
Paper presented at the meeting of the Association for Education in Journalism and Mass Communication, Montreal, Canada.

Geissler, J., \& Horridge, P. (1993). [Online]. University student's computer knowledge and commitment to learning. Available: <http:// www.elibrary,comgetdoc.cig?id $=65187586 \times 0 y 247 \&$ Form $=$ EN\&Button=MEM\&OIDS=0Q001D000\&pubname= Joumal_of_Research_on_Computing_in_Education\&puburl1 $=0>$ VU World Wide Web User Survey (1996]. [Online]. Available: <http://www.cc.gatech.edu/gvu/ uder_surveys/survey-10-1996/>

Kendrick, A. (1995). Survey of computer facilities and usage by $A A F$ member schools. Unpublished report.

Kimbrough, J. (1992), Creative computing. In L. N. Reid (Eds.), Proceedings of the 1992 Conference of the American Academy of Advertising (pp. 1112).

Norusis, S. (1988). SPSS/PC+ v2.o base manual. Chicago, IL, SPSS Inc.

Novitzki, J. E. (1991). "The level of computer use in schools of business." Journal of Research on Computing in Education, 23(3), 452-462.

Rappoport, J. (1996). "Cyber-grads: Savvy students hit the net." Advertising Age, May 13, p. 36.

Reed, W. M. (1990). "The effect of computer-andwriting instruction on prospective English teachers' attitudes toward and perceived uses of computers in writing instruction." Journal of Research on Computing in Education, 23(1), 3-27.

Shields, M. (1996). "Academe and the technology totem." Education Digest, 61, 43-47.

Smith, W. E. (1994). "Computer-mediated communication: An experimental study." Journalism Educator, 48(4), 27-33.

Wagner, E. (1992). Computer is just another tool. In L. N. Reid (Eds.), Proceedings of the 1992 Conference of the American Academy of Advertising (pp. 15-16). 